\title{
Selective Detection of Protein Secondary Structural Changes in Solution Protein- Polysaccharide Complexes Using Vibrational Circular Dichroism (VCD)
}

\author{
Timothy R. Rudd ${ }^{\mathrm{a}}$, Richard J. Nichols ${ }^{\mathrm{b}}$ and Edwin A. Yates ${ }^{\mathrm{a}}$ \\ ${ }^{a}$ School of Biological Sciences, ${ }^{b}$ Department of Chemistry, \\ University of Liverpool, Liverpool L69 7ZB Great Britain
}

\section{Supporting Information}

\section{Experimental Information}

Circular dichroism spectroscopy

Synchrotron radiation circular dichroism (SRCD) spectra were recorded on the purpose-built CD-12 beamline at Daresbury Laboratory, (Warrington, UK), between 310 and $180 \mathrm{~nm}$ in $\mathrm{D}_{2} \mathrm{O}$, using a $0.1 \mathrm{~mm}$ quartz cell and $1 \mathrm{~nm}$ resolution. Results are expressed as molar ellipticity $\left(\mathrm{mol}^{-1} \mathrm{~cm}^{-1}\right)$ with reference to a solution of (+)-10-camphorsulfonic acid (CSA) at $10 \mathrm{mg} \cdot \mathrm{ml}^{-1}$ in water.

Figure 1. Spectra of Antithrombin were recorded at $1 \mathrm{mg} \cdot \mathrm{mL}^{-1}$ and heparin at $0.33 \mathrm{mg} \cdot \mathrm{mL}^{-1}$ in PBS.

FTIR \&Vibrational Circular Dichroism (VCD)

FTIR \&VCD spectra were recorded on a Bruker IFS 66v/S spectrometer, with the PMA 37 external compartment (Bruker Optics Limited, Coventry, UK), using a MCT liquid nitrogen cooled detector. The VCD spectra were composed of 6 blocks of 1000 scans and averaged, at a resolution of $4 \mathrm{~cm}^{-1}$, using an Omnicell sample holder with $\mathrm{BaF}_{2}$ windows (Specac Ltd., Orpington, Kent, UK), with the spectrometer purged with nitrogen gas. The raw VCD spectra were handled in the following manner to produce absorbance spectra, $\Delta \mathrm{A}$ :

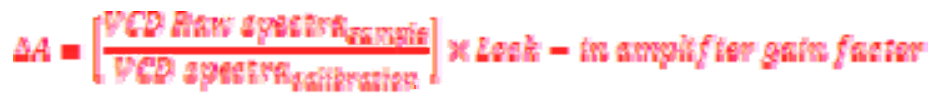

where:

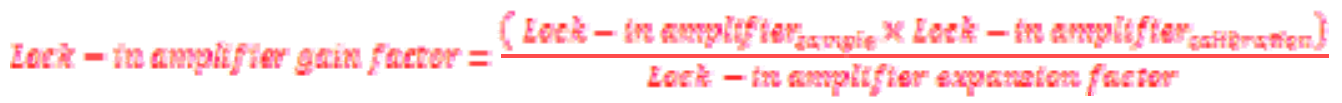

The FTIR spectra were performed at a resolution of $2 \mathrm{~cm}^{-1}$, with each spectrum composed of 2000 scans. Protein samples were made up in $\mathrm{D}_{2} \mathrm{O}$ PBS and the polysaccharide spectra were recorded in $\mathrm{D}_{2} \mathrm{O}$ at $25 \mathrm{mg} / \mathrm{mL}$. 


\section{Bovine serum albumin:Heparin Complex VCD spectra}

Another example of the selective observation of protein secondary structure changes using VCD is shown below (Figure S1.); bovine serum albumin (BSA) (100 mg.mL $\mathrm{m}^{-1}$ ) is observed binding to heparin (33 mg.mL $\mathrm{m}^{-1}$ ). The VCD spectrum of heparin is featureless (Figure S1 A). The addition of heparin to BSA causes a drastic secondary structure change (Figures S1 C \& D). There are a number of factors that are known to cause sample to sample variation in protein VCD spectra, including deuteriuem exchange with amides and concentration ${ }^{1,2}$.

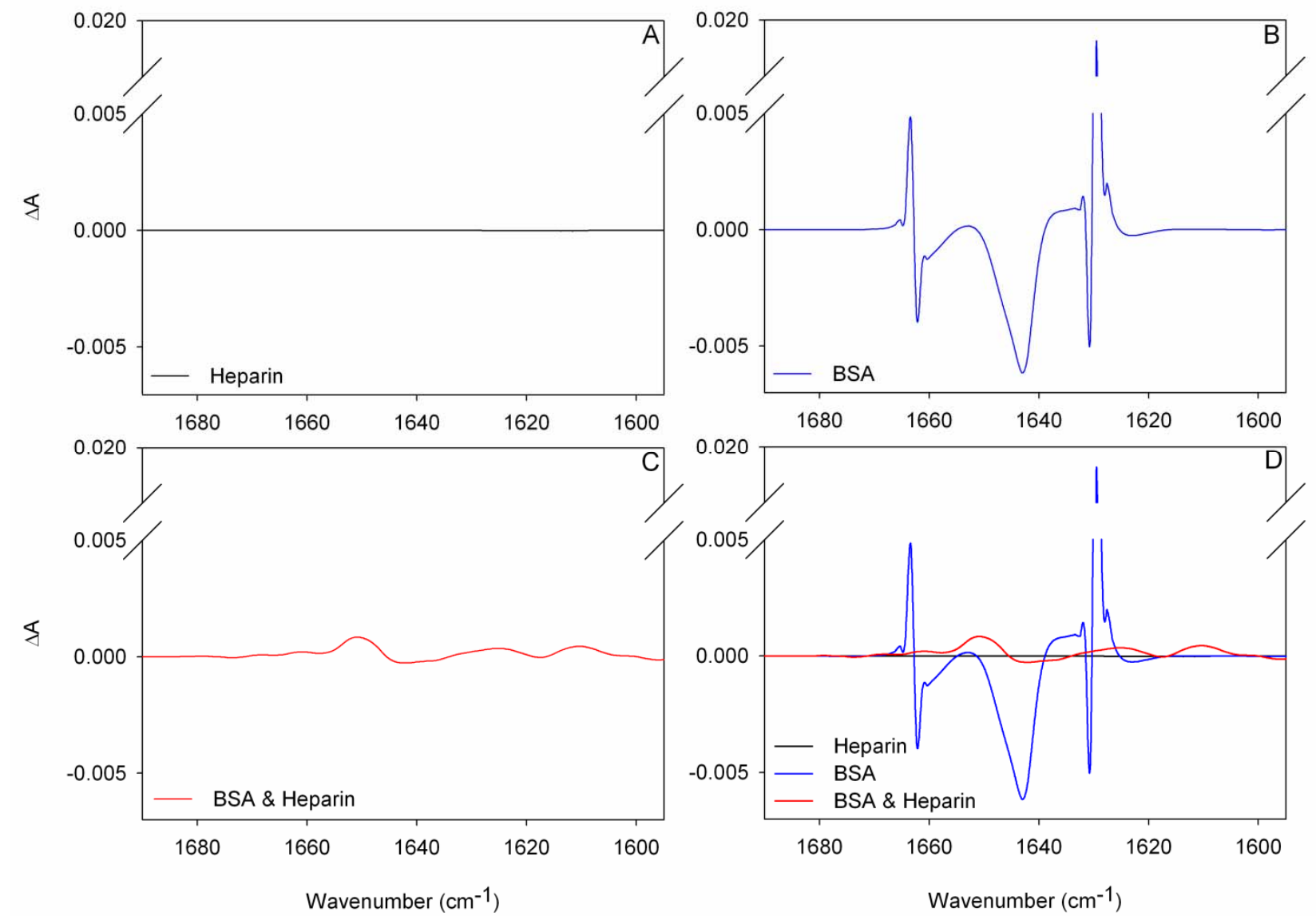

Figure S1. VCD spectra of BSA (B) interacting with heparin (A), the addition of heparin to BSA causes a dramatic change in secondary structure (C \& D)

\section{VCD spectra of selected polysaccharides.}

In the manuscript, 3 examples are given of VCD of GAGs; heparin, heparan sulfate and chrondroitin sulfate B. The spectrum of heparin is featureless in the Amide I' region and so are chemically modified heparins (Figure S2). In this case, both $N$-acetylated and 2-de-O-sulfated heparin exhibit the same flat spectra. Also shown are exhaustively ion exchanged cation-heparin complexes $\left(\mathrm{Cu}^{2+}\right.$ $\mathrm{Mg}^{2+}$ and $\mathrm{Zn}^{2+}$ ), these are relevant because in Rudd et al. $2007^{3}$ it is shown that the heparin associated with specific cations can change the conformation of the polysaccharide and consequently their electronic circular dichroism spectra. Here both copper and 
zinc ions have some effect, but the signals are still two orders of magnitude lower than the equivalent Molar concentration of BSA. Chondroitin sulfate A and C are also shown for completeness, both having strong bands although, again, these are two orders of magnitude smaller than bands for BSA in the Amide I' region. VCD has also been extensively used to study other features of carbohydrate structure $^{4-7}$.
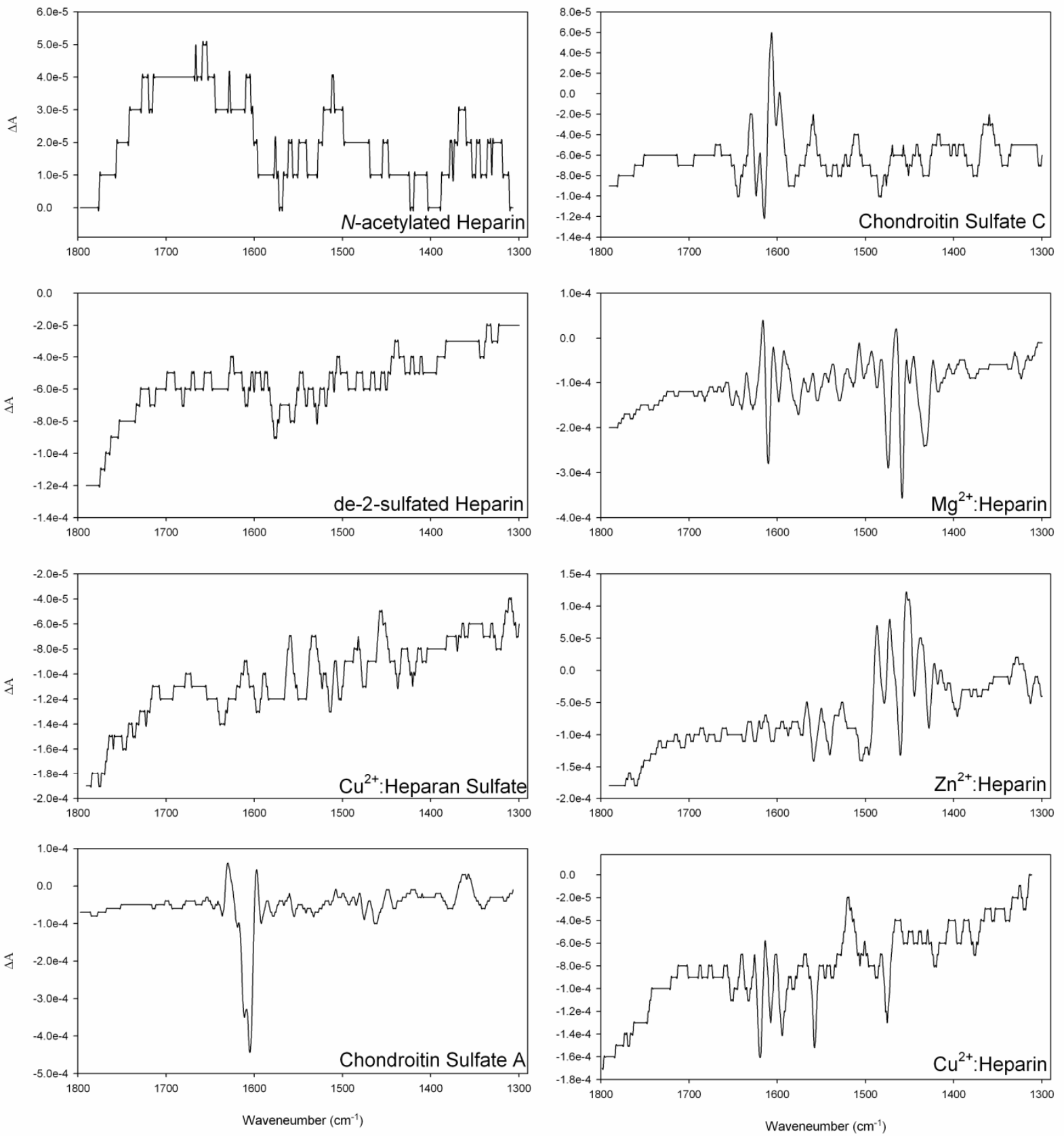

Figure S2. VCD spectra of various glycosaminoglycans. All samples were recorded at a concentration of $25 \mathrm{mg}^{\mathrm{m}} \mathrm{mL}^{-1}$ in $\mathrm{D}_{2} \mathrm{O}$. 
References

(1) Diem, M. J. Am. Chem. Soc. 1988, 110, 6967-6970.

(2) Taniguchi, T.; Miura, N.; Nishimura, S. I.; Monde, K. Mol. Nutr. Food Res. 2004, 48, 246-254.

(3) Rudd, T. R.; Guimond, S. E.; Skidmore, M. A.; Duchesne, L.; Guerrini, M.; Torri, G.; Cosentino, C.; Brown, A.; Clarke, D. T.; Turnbull, J. E.; Fernig, D. G.; Yates, E. A. Glycobiology 2007, 17, 983-993.

(4) Bose, P. K.; Polavarapu, P. L. Carbohydr. Res. 1999, 322, 135-141.

(5) Bose, P. K.; Polavarapu, P. L. Carbohydr. Res. 1999, 319, 172-183.

(6) Nakahashi, A.; Taniguchi, T.; Miura, N.; Monde, K. Org. Letts. 2007, 9, 4741-4744.

(7) Petrovic, A. G.; Bose, P. K.; Polavarapu, P. L. Carbohydr. Res. 2004, 339, 2713-2720. 